\title{
ABCC7/CFTR Expression is Down-regulated in Patients with Active Ulcerative Colitis
}

\section{Marco Antonio Villeda-Ramírez}

Instituto Nacional de Ciencias Medicas y Nutricion Salvador Zubiran Clinica de Enfermedad Inflamatoria Intestinal

\section{Daniela Meza-Guillen}

Instituto Nacional de Ciencias Medicas y Nutricion Salvador Zubiran Clinica de Enfermedad Inflamatoria Intestinal

\section{Rafael Barreto-Zúñiga}

Instituto Nacional de Ciencias Medicas y Nutricion Salvador Zubiran Clinica de Enfermedad Inflamatoria Intestinal

Jesus Yamamoto-Furusho ( $\sim$ kazuofurusho@hotmail.com )

IBD Clinic, Instituto Nacional de Ciencias Medicas y Nutricion Salvador Zubiran https://orcid.org/00000002-5247-5812

\section{Short Report}

Keywords: ATP Binding Cassette subfamily C member 7 (ABCC7/CFTR) gene and protein expression, Ulcerative Colitis, clinical characteristics

Posted Date: April 15th, 2020

DOI: https://doi.org/10.21203/rs.3.rs-22104/v1

License: (c) (1) This work is licensed under a Creative Commons Attribution 4.0 International License. Read Full License 


\section{Abstract}

Background Inflammatory Bowel Disease includes Ulcerative Colitis (UC) and Crohn's disease (CD) of unknown etiology. The expression of ATP Binding Cassette Family proteins (ABC) has been associated with drug resistance and development of UC. The Cystic Fibrosis Transmembrane Conductance Regulator (CFTR) or also known as $A B C C 7$ is involved in the inflammatory chronic response. The aim of the study was to evaluate the role of ABCC7/CFTR in UC patients and normal controls without inflammation.

Results A total of 62 patients with UC and normal controls were included. We found a significant downregulation of CFTR gene expression in patients with active UC compared to remission UC and normal controls without inflammation ( $\mathrm{P}<0.004$ and $\mathrm{P}<0.0001$ respectively) even the gene expression of CFTR was decreased in remission UC patients compared to normal controls $(P=0.047)$. The CFTR gene expression was associated with persistent activity of $\mathrm{UC}$ and young age at diagnosis before 40 years. The protein expression of CFTR was decreased in severe active UC patients compared to normal controls without inflammation.

Conclusion The CFTR gene and protein expression were significantly decreased in active UC patients and it was also associated with clinical outcomes.

\section{Background}

The Ulcerative Colitis (UC) is a chronic inflammatory condition of the colon that affects only the colonic mucosa of unknown etiology. The clinical symptoms includes rectal bleeding, chronic diarrhea and abdominal pain ${ }^{1,2}$. It has been proposed that innate and adaptive immunity are involved in the inflammatory response, specifically UC had increase the production of pro-inflammatory interleukins such as IL1, IL6 and IL8 as a result of activation of the transcriptional nuclear factor Nuclear KB (NF-KB) ${ }^{3-5}$.

Recently, genes that encodes for a family of $A B C$ transmembranal multidrug resistant proteins (ABC, ATP Binding Cassette family) have been associated with medical response and clinical course of disease ${ }^{6}$. The $A B C$ family is composed by 48 transmembranal proteins grouped in 7 subfamilies (ABCCA-ABCCG) 7,8. The ABCC member 7 (ABCC7), also known Cystic Fibrosis Transmembrane-conductance Regulator (CFTR) is an ionic channel that actively participates in the regulation of elimination and absorption of chloride ion in different tissues including the gastrointestinal tract 9,10 .

The presence of mutation in the ABCC7/CFTR gene has been associated with cystic fibrosis (CF) which is a prevalent disease in white populations, dysfunction and changes in gene expression has been implicated in other diseases development, including chronic inflammation ${ }^{11,12}$. In patients with CF has been observed an increase of fecal calprotectin as same as happens in the inflammatory bowel disease $(\mathrm{IBD})^{13-15}$. The ABCC7/CFTR knock-out mice model developed intestinal inflammation suggesting a role of this gene in the gut inflammation ${ }^{12,16}$. The levels of $A B C C 7 / C F T R$ expression have been involved in modulating the NF-KB activity and the production of IL8 and IL6 production in lung cell lines ${ }^{17-19}$. The 
aim of this study was determinate the ABCC7/CFTR gene and protein expression in UC patients and its association with clinical outcomes.

\section{Results}

\subsection{Demographic and clinical characteristics of UC patients}

A total of 41 patients with UC were included in the study, $52 \%$ were male, mean age of $43.5 \pm 15.1$ years, age at diagnosis $<40$ years in $83 \%$. All demographic and clinical characteristics are shown in Table 1.

Table 1

Correlation of relative gene expression of ABCC7/CFTR and clinical characteristics of UC patients.

\begin{tabular}{|c|c|c|c|c|c|}
\hline Clinical characteristics & & $n$ & $\%$ & $\begin{array}{l}\text { ABCC7/CFTR } \\
\text { Expression }\end{array}$ & $P$ \\
\hline Gender & $\begin{array}{l}\text { Male } \\
\text { Female }\end{array}$ & $\begin{array}{l}21 \\
20\end{array}$ & $\begin{array}{l}52 \\
48\end{array}$ & & \\
\hline Age at diagnosis & $\begin{array}{l}<40 \\
>40\end{array}$ & $\begin{array}{l}34 \\
7\end{array}$ & $\begin{array}{l}83 \\
17\end{array}$ & $\begin{array}{l}19.37 \\
28.93\end{array}$ & 0.745 \\
\hline $\begin{array}{l}\text { Extraintestinal } \\
\text { manifestations }\end{array}$ & $\begin{array}{l}\text { Present } \\
\text { Absent }\end{array}$ & $\begin{array}{l}27 \\
14\end{array}$ & $\begin{array}{l}65 \\
35\end{array}$ & $\begin{array}{l}19.24 \\
24.39\end{array}$ & 0.191 \\
\hline Extent of disease & $\begin{array}{l}\text { Distal colitis } \\
\text { Pancolitis }\end{array}$ & $\begin{array}{l}19 \\
22\end{array}$ & $\begin{array}{l}46 \\
54\end{array}$ & $\begin{array}{l}21.71 \\
20.39\end{array}$ & 0.724 \\
\hline Years of evolution & $\begin{array}{l}<3 \\
>3\end{array}$ & $\begin{array}{l}7 \\
34\end{array}$ & $\begin{array}{l}17 \\
83\end{array}$ & $\begin{array}{l}14.57 \\
22.32\end{array}$ & 0.119 \\
\hline Clinical course of disease & $\begin{array}{l}\text { Inactive } \\
\text { Long-term remission } \\
\text { Persistent activity }\end{array}$ & $\begin{array}{l}31 \\
5 \\
5\end{array}$ & $\begin{array}{l}76 \\
12 \\
12\end{array}$ & $\begin{array}{l}25.64 \\
20.78 \\
14.63\end{array}$ & $\begin{array}{l}0.005^{*} \\
\text { OR }=21.7 \\
\text { IC }=3.59-132.0\end{array}$ \\
\hline
\end{tabular}

\subsection{Gene and Protein Expression of CFTR/ABCC7 and IL6 in tissue samples from UC patients}

We found a down-regulation of the gene expression of CFTR in active UC group compared to control without inflammation and UC remission patients $(P<0.001, P<0.004$ respectively). We also identify that the expression of CFTR was down-regulated in UC remission group compared with control without inflammation $(P<0.04)$ as shown in Fig. 1. In protein expression we observed low expression of CFTR/ABCC7 in biopsies of the active UC compared with remission UC and control group $(P=0.046)$, no difference was observed in remission UC group compared with control (Fig. 2).

The IL-6 gene expression was measured in colonic biopsies from UC patients in order to determine the presence of inflammation and it was also correlated with histological activity. The IL- 6 gene expression was low in controls without inflammation and UC remission patients compared to active UC group $(\mathrm{P}<$ 
0.001). The gene expression of IL-6 in UC remission group and control without inflammation was similar in both groups as shown in Fig. 3 .

A down-regulation of $A B C C 7 / C F T R$ gene expression was associated with persistent activity $(P=0.005$, $\mathrm{OR}=21.7$ and $\mathrm{Cl}=3.59-132.0)$.

\section{Discussion}

Our best knowledge, this is the first study that showed a down-regulation of the gene and protein expression of CFTR or ABCC7 in patients with active UC compared to UC in remission and normal controls without inflammation. It is important to note that low CFTR gene expression was significant associated with young age at diagnosis ( $<40$ years old) and a clinical course characterized by persistent UC activity.

It is well known that CFTR has been widely studied in cystic fibrosis (CF) and recently, it has grown interest in to study its role in other diseases or inflammatory conditions such as in the biliary epithelium and intestine ${ }^{12,22-24}$. In animal models and in vitro studies have demonstrated the role of CFTR in the intestinal inflammatory process characterized by histological infiltration of immune cells and increased of inflammatory fecal biomarkers ${ }^{13-16}$.

Our findings are similar to that reported by Werlin et al. and Lee et al. who found increased levels of fecal calprotectin in children with $\mathrm{CF}^{13,15}$. In vitro studies have demonstrated that a down-regulation of CFTR is contributing to chronic inflammation as we found in patients with active UC. This could be explained by findings reported by Wang et al who reported the effect of mutant ABCC7/CFTR in bronchial epithelial cell line (CFBE cells) during TNFa recombinant stimulation, they observed that ABCC7/CFTR mutant increase the activity of transcriptional nuclear factor $\mathrm{KB}(\mathrm{NF}-\mathrm{kB})$ and production of pro-inflammatory cytokines compared to those with normal function of $\mathrm{CFTR}^{17}$.

Similar findings by Defu Li et al. who found increase in the NF-KB activity, IL-8 and IL-6 production in human bronchial epithelial cells (16HBE) that had a down-regulation of $A B C C 7 / \mathrm{CFTR}^{18}$ as well as in patients with human lung adenocarcinoma cell lines ${ }^{25}$. In other cell lines from colorectal carcinoma, Crites $\mathrm{K}$ et al reported that a down-regulation of ABCC7/CFTR increased the production of IL- 6 , IL- $1 \beta$ and IL-8 in CACO2 and HT29 cells due to the activation of ERK1/2, MAPK, IKBa and NF-KB pathways ${ }^{26}$. In a knock-out animal model of $A B C C 7 / C F T R$, they found that the down regulation of CFTR produced inflammation through the increased of NF-KB, TNFa and IL-6 in the mouse intestine, CACO2 cells and colangiocytes stimulated by lipopolysaccharides from Escherichia coli ${ }^{2326,27}$. In other study performed in rats and 16HBE140 cells found that down-regulation of CFTR increased the production of IL-8 compared to those that overexpressed CFTR with lack of MAPK/NF-KB activation ${ }^{19}$ and the same finding was also observed in mutant CFTR (DF508) mice and HaCaT cells that the down-regulation of the CFTR expression exhibited inflammation and delayed cutaneous wound healing ${ }^{28}$. 
Our findings are similar to above mentioned studies confirming the role of down-regulation of CFTR in the development of inflammatory process in patients with active UC.

Nevertheless, it already known that CFTR interacts with a variety of proteins and regulates its function ${ }^{10}$. Recent studies have demonstrated in Cftr knock-out mice model higher levels of IL-17 compared to wild type mouse during infection with Pseudomonas aeruginosa and resulting in the perpetuation of inflammatory process by neutrophil recruitment suggesting that the absence of CFTR contributes to the inflammation by IL17 production ${ }^{29}$ and have been also observed in patients with active UC ${ }^{30}$.

The CFTR is a channel expressed in the intestine that regulates the efflux of chloride and bicarbonate ions and also participates actively in the $\mathrm{pH}$ regulation ${ }^{9,10}$. A proposed hypothesis explaining the role of CFTR in UC patients is that down-regulation of CFTR affects the $\mathrm{pH}$ balance in the colon producing a decreased expression of MUC11 and MUC12 contributing to the adherence of bacteria and promoting the colonic inflammation $10,11,31$ and it was reported by our group a decreased gene expression of MUC20 in patients with active UC compared to UC remission and normal controls ${ }^{32}$.

On the other hand, changes in the intestinal $\mathrm{pH}$ and decreased MUC11 and MUC12 expression promotes the colonization of phatobiontic microbiota in the intestinal lumen as it has been reported in IBD patients ${ }^{11,23,33}$. Phatobiontic microbiota increased the expression, recognition and activation of TLR4 with activation of NF-KB and subsequent production of pro-inflammatory cytokines such as IL- 6 and IL$8{ }^{23,26,27,33,34}$ Microbiota dysbiosis is associated with reduction of short-chain fatty acids, an antiinflammatory molecules that regulates the immune response in the intestine, this fatty acids ameliorates the intestinal inflammation in IBD in animal model. ${ }^{35}$ But, is possible that down-regulation of ABCC7/CFTR contribute to IL17 up-regulation in patients with UC allowing the persistent activity as we observed in the active group in our study. ${ }^{29,30}$

\section{Conclusions}

In conclusion, a down-regulation of gene and protein expression of CFTR was found in patients with active UC suggesting the role of CFTR in the development of colonic inflammation. The CFTR downregulation was associated with young age at diagnosis and persistent activity clinical course.

\section{Material And Methods}

We included 62 individuals who were divided in 3 groups: active UC $(n=20)$, remission UC $(n=21)$ and normal controls without inflammation $(n=21)$. All patients belonged to the Inflammatory Bowel Disease Clinic at the Instituto Nacional de Ciencias Medicas y Nutrición Salvador Zubirán. All patients had a definitive diagnosis of UC confirmed by histopathology. All demographical and clinical variables were collected from interview and medical records such as: age at diagnosis, gender, type of medical treatment (5-aminosalycilates, steroids, thiopurines, biologic therapy), disease extension or location according to Montreal Classification, the presence of extra-intestinal manifestations such as articular affection, 
ankylosing spondylitis, sacroiliitis, sclerosing cholangitis, pyoderma gangrenosum, erythema nodosum or uveitis and clinical course classified as: initially active and then prolonged remission (first episode with activity and then long-term remission for more than 5 years), intermittent activity ( $>2$ relapses per year) and chronic continual activity (persistent activity despite medical conventional therapy). The clinical and endoscopic activity was determined by Mayo and histological activity by Riley score. ${ }^{20,21}$

\section{Tissue samples and Gene Expression Analysis}

All colonic biopsies were taken by colonoscopy with informed consensus of all the patients that participate in the study, immediately placed in RNA Later (Ambion, Austin, Tx, USA) and stored at $-70^{\circ} \mathrm{C}$ until processing. Total RNA extraction from colonic biopsies was made using RNA extraction kit (High Pure RNA Tissue Kit, Roche). The biological sample was mixed by homogenizer Polytron $\rightarrow$ LD1300 for 1 minute, the RNA was extracted by commercial kit for RNA extraction High Pure RNA Tisseu kit (Roche区) after the incubation with DNAase for 20 minutes and was diluted in $50 \mu \mathrm{l}$ of elution buffer and stored at $-70^{\circ} \mathrm{C}$. The integrity of RNAm was evaluated by electrophoresis in an agarose gel at $1 \%$ with ethidium bromide, it was then visualized using an UVP dual-intensity transluminator.

The cDNA was synthetized through reverse transcription with the cDNA Transcription Synthesis kit (Roche区) under a preincubation at $25^{\circ} \mathrm{C} \times 10$ minutes, incubation at $55^{\circ} \mathrm{C} \times 30$ minutes, followed by denaturalization at $85^{\circ} \mathrm{C} \times 5$ minutes in the GeneAmp PCR Systems thermocycler (Perkin-Elmer区). The ARNm expression of ABCC7/CFTR was measured by Real Time Polymerase Chain Reaction and $\beta$-actin was used as reference gene. The IL6 gene expression was used as inflammation marker as previously reported and demonstrated good correlation with histologic activity. For determining the ABCC7/CFTR, IL6 and $\beta$ actin expression we used a set of designed forward and reverse primers (ABCC7/CFTR left: ctgactgtttccatcaagggta, right: gcagtcttcttaagagtcagtttgg; IL-6 left: gatgagtacaaaagtcctgatcca, right: ctgcagccactggttctgt; $\beta$ actin left: tccaaatatgagatgcgttgtt, right: tgctatcacctcccctgtgt) and a mix of Taq

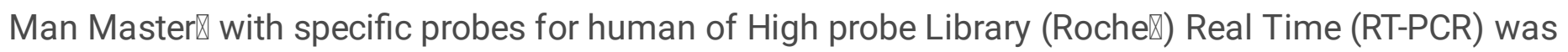
performed in Light Cycler 2.0 Roche冈 tehermocycler, under a program of 1 cycle of denaturized $\left(95^{\circ} \mathrm{C} \mathrm{x}\right.$ 10 minute), 45 cycles of amplification $\left(95^{\circ} \mathrm{C} \times 10\right.$ seconds, alignment $60^{\circ} \mathrm{C} \times 10$ seconds, extension $40^{\circ} \mathrm{C} \times 30$ seconds) and 1 cycle of cooling $\left(40^{\circ} \mathrm{C} \times 30\right.$ seconds $)$.

\section{Protein Expression Analysis by Western Blot Analysis}

The total protein of colon tissues samples 4 patients per group (active and remission UC and control group) was extracted with solution of RIPA buffer (Siagma-Aldrich) and cocktail of Proteases inhibitor (Roche), and quantified by Bradford assay (Bio-Rad, Hercules, CA, USA), and stored at-70C. The protein detection was performed by electrophoresis in SDS-PAGE and then transferred to polyvinylidene difluoride membranes. All blots were blocked with $3 \%$ BSA for $60 \mathrm{~min}$ at room temperature and incubated overnight at 4 with primary antibodies. The primary antibodies for CFTR/ABCC7 were used in a concentration of $1: 1000$ and $\beta$-actin was used to normalize the data in a concentration of 1:10000. The blots were incubated with anti-rabbit secondary antibodies conjugated with horseradish peroxidase (1:3000). 
Images were analyzed with a ChemiDocTM XRS + System Image LabTM Software (Bio-Rad, Hercules, CA, USA) and the western blot analysis was performed using independent blots.

\section{Statistical Analysis}

The statistical analysis was performed using SPSS version 17.0, using Kruskall Wallis non-parametric test, Spearman`s correlation, Fisher's exact test and Odds Ratio (OR) in order to determine the strength of association. Protein expression statistical analysis was done by using one-way analysis of variance on ranks by Dunn's method for all pairwise multiple comparison procedure (Sigma Stat 11.2 program, Aspire Software International, Leesburg, VA, USA). Data were expressed as median, range, and mean \pm standard deviation (SD)/standard Error of the mean (SEM). A P value $<0.05$ was considered as statistical significant.

\section{Declarations}

\section{Ethics approval and consent to participate}

This study was performed according to the principles expressed in the Declaration of Helsinki. This study was approved by the Ethical and Research Committee at the Instituto Nacional de Ciencias Médicas y Nutrición (REF. GAS-2724-18-21-1), and a written informed consent was obtained from all subjects.

\section{Funding}

This work was supported by the Consejo Nacional de Ciencia y Tecnologia, Mexico City, Mexico with project number 281775 .

\section{Author contributions}

Villeda-Ramírez MA and Yamamoto-Furusho JK conceived, designed the project contributed also wrote the paper. Villeda-Ramirez MA and Meza-Guillen D contributed to participant recruitment performed the expreiments, data collection and analysis. Barreto-Zuñiga R provided the biopsies during colonoscopy study.

\section{Acknowledgements}

Not applicable

\section{Conflicts of interest}


The authors declare that they have no competing interests.

\section{References}

1. Ananthakrishnan AN, Bernstein CN, lliopoulos D, et al. Environmental triggers in IBD: A review of progress and evidence. Nat Rev Gastroenterol Hepatol. 2018;15(1):39-49. doi:.

2. Murugan R, Saravanan S, Parimelazhagan T. Study of intestinal anti-inflammatory activity of Phoenix loureiroi Kunth (Arecaceae) fruit. Biomed Pharmacother. 2017;93:156-64. doi:.

3. $10.1155 / 2017 / 5126048$

Luo C, Zhang H. The Role of Proinflammatory Pathways in the Pathogenesis of Colitis-Associated Colorectal Cancer. Mediators Inflamm. 2017;2017. doi:.

4. Geremia A, Biancheri P, Allan P, Corazza GR, Di Sabatino A. Innate and adaptive immunity in inflammatory bowel disease. Autoimmun Rev. 2014;13(1):3-10. doi:.

5. Lu Y, Li X, Liu S, Zhang Y, Zhang D. Toll-like receptors and inflammatory bowel disease. Front Immunol. 2018;9(JAN):1-9. doi:.

6. Yamamoto-Furusho JK, Villeda-Ramírez MA, Fonseca-Camarillo G, et al. High gene expression of MDR1 (ABCB1) is associated with medical treatment response and long-term remission in patients with ulcerative colitis. Inflamm Bowel Dis. 2010;16(4):541-2. doi:.

7. Sodani K, Patel A, Kathawala RJ, Chen Z-S. Multidrug resistance associated proteins in multidrug resistance. Chin J Cancer. 2012;31(2):58-72. doi:.

8. Zhang Y-K, Wang Y-J, Gupta P, Chen Z-S. Multidrug Resistance Proteins (MRPs) and Cancer Therapy. AAPS J. 2015;17(4):802-12. doi:.

9. Saint-Criq V, Gray MA. Role of CFTR in epithelial physiology. Cell Mol Life Sci. 2017;74(1):93-115. doi:.

10. Lim SH, Legere EA, Snider J, Stagljar I. Recent progress in CFTR interactome mapping and its importance for cystic fibrosis. Front Pharmacol. 2018;8(JAN):1-9. doi:.

11. Lynch SV, Goldfarb KC, Wild YK, Kong W, De Lisle RC, Brodie EL. Cystic fibrosis transmembrane conductance regulator knockout mice exhibit aberrant gastrointestinal microbiota. Gut Microbes. 2013;4(1):41-7. doi:.

12. Munck A. Cystic fibrosis: Evidence for gut inflammation. Int J Biochem Cell Biol. 2014;52:180-3. doi:.

13. Lee JM, Leach ST, Katz T, Day AS, Jaffe A, Ooi CY. Update of faecal markers of inflammation in children with cystic fibrosis. Mediators Inflamm. 2012;2012. doi:.

14. Rumman N, Sultan M, El-Chammas K, et al. Calprotectin in Cystic Fibrosis. BMC Pediatr. 2014;14(1):1-7. doi:.

15. Werlin SL, Benuri-silbiger I, Kerem E, et al. Evidence of Intestinal Inflammation in Patients With Cystic Fibrosis. 2010;51(3):304-308. doi:.

16. Stellari F, Bergamini G, Ruscitti F, et al. In vivo monitoring of lung inflammation in CFTR-deficient mice. J Transl Med. 2016;14(1):1-9. doi:. 
17. Wang H, Cebotaru L, Lee HW, et al. CFTR Controls the Activity of NF-kB by Enhancing the Degradation of TRADD. Cell Physiol Biochem. 2016;40(5):1063-78. doi:.

18. Li D, Wang J, Sun D, et al. Tanshinone IIA sulfonate protects against cigarette smoke-induced COPD and down-regulation of CFTR in mice. Sci Rep. 2018;8(1):1-13. doi:.

19. Dong ZW, Chen J, Ruan YC, et al. CFTR-regulated MAPK/NF-K B signaling in pulmonary inflammation in thermal inhalation injury. Sci Rep. 2015;5(May):1-13. doi:.

20. Hospital H, Infirmary L, Hospital BG. Clinical trials Comparison of delayed release 5 aminosalicylic acid (mesalazine) and sulphasalazine in the treatment of mild to moderate ulcerative colitis relapse. 1988:669-674.

21. The New England Journal of Medicine Downloaded from nejm.org at Yale University on July 7. 2015. For personal use only. No other uses without permission. From the NEJM Archive. Copyright (C 2010 Massachusetts Medical Society. All rights reserved. 2010.

22. Scirpo R, Fiorotto R, Villani A, et al. HHS Public Access. 2016;62(5):1551-62. doi:.

23. Kleme ML, Sané AT, Garofalo C, Levy E. Targeted CFTR gene disruption with zinc-finger nucleases in human intestinal epithelial cells induces oxidative stress and inflammation. Int J Biochem Cell Biol. 2016;74:84-94. doi:.

24. Fiorotto R, Villani A, Kourtidis A, et al. The cystic fibrosis transmembrane conductance regulator controls biliary epithelial inflammation and permeability by regulating Src tyrosine kinase activity. Hepatology. 2016;64(6):2118-34. doi:.

25. Hunter MJ, Treharne KJ, Winter AK, Cassidy DM, Land S, Mehta A. Expression of wild-type CFTR suppresses NF-KB-driven inflammatory signalling. PLoS One. 2010;5(7). doi:.

26. Crites KSM, Morin G, Orlando V, et al. CFTR Knockdown induces proinflammatory changes in intestinal epithelial cells. J Inflamm (United Kingdom). 2015;12(1):1-15. doi:.

27. Liu K, Zhang X, Zhang JT, Tsang LL, Jiang X, Chan HC. Defective CFTR- beta-catenin interaction promotes NF-kappaB nuclear translocation and intestinal inflammation in cystic fibrosis. Oncotarget. 2016;7(39). doi:.

28. Chen J, Chen Y, Chen Y, et al. Epidermal CFTR Suppresses MAPK/NF-kB to Promote Cutaneous Wound Healing. Cell Physiol Biochem. 2016;39(6):2262-74. doi:.

29. Hsu D, Taylor P, Fletcher D, et al. CF Lung Infection and Inflammation: IL-17 Pathophysiology and Therapeutic Intervention. Infect Immun. 2016;84(9):2410-21. doi:.

30. Fonseca-Camarillo G, Mendivil-Rangel E, Furuzawa-Carballeda J, Yamamoto-Furusho JK. Interleukin 17 gene and protein expression are increased in patients with ulcerative colitis. Inflamm Bowel Dis. 2011;17(10):E135-6. doi:.

31. Garg M, Ooi CY. The Enigmatic Gut in Cystic Fibrosis: Linking Inflammation, Dysbiosis, and the Increased Risk of Malignancy. Curr Gastroenterol Rep. 2017;19(2). doi:.

32. Yamamoto-furusho JK, Ascaño-gutiérrez I, Furuzawa-carballeda J. Fonseca-camarillo G. Patients with Active and Remission Ulcerative Colitis. 2015;2015. 
33. Fiorotto R, Scirpo R, Trauner M, et al. Loss of CFTR affects biliary epithelium innate immunity and causes TLR4NF-KB-mediated inflammatory response in mice. Gastroenterology. 2011;141(4):1498508.e5. doi:.

34. Mitchell S, Vargas J, Hoffmann A. Signaling via the NFkB system. Wiley Interdiscip Rev Syst Biol Med. 2016;8(3):227-41. doi:.

35. Sun M, Wu W, Liu Z, Cong Y. Microbiota metabolite short chain fatty acids, GPCR, and inflammatory bowel diseases. J Gastroenterol. 2017;52(1):1-8. doi:.

\section{Figures}

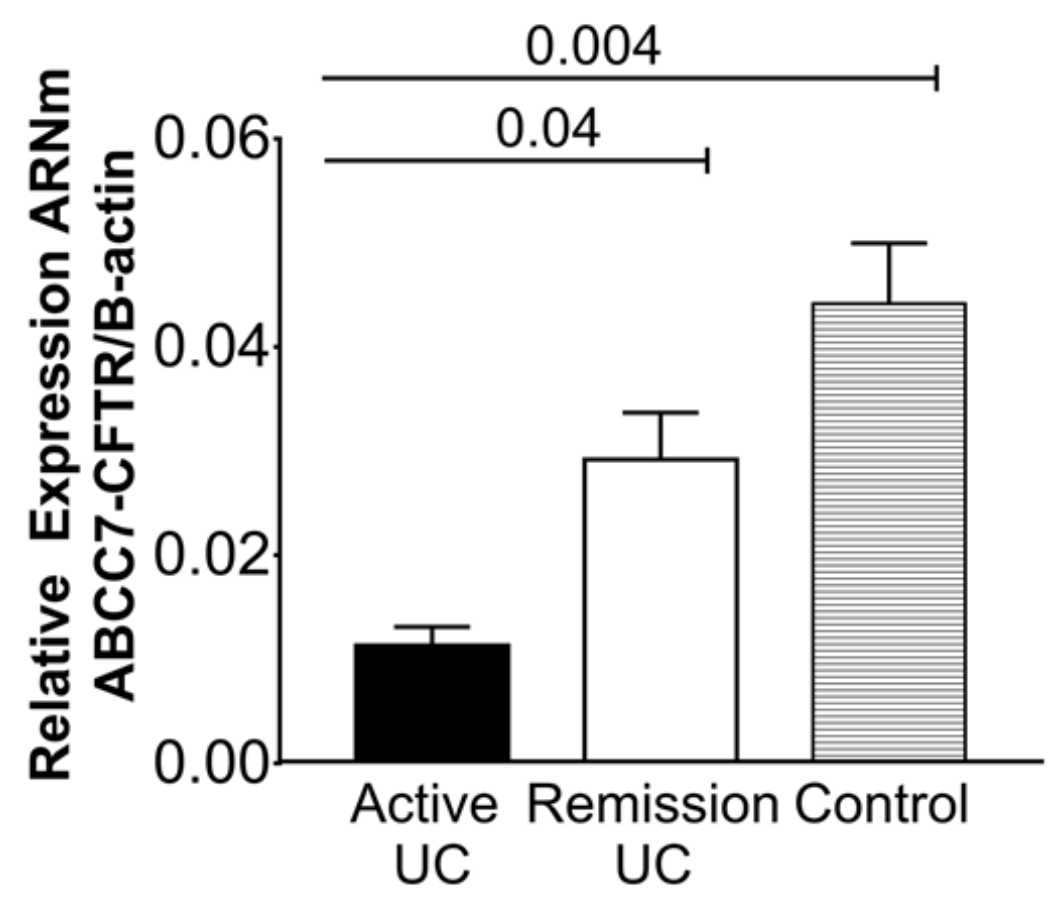

\section{Figure 1}

Relative gene expression of $A B C C 7 / C F T R$ in biopsies of UC patients. The relative gene expressions of $A B C 7 / C F T R$ were compared in patients with active, remission UC and control group. The medians of 
relative expression in the tree groups were compared with $\mathrm{H}$-Kruskall Wallis and individual groups were analyzed by U-Mann-Withney test.

A

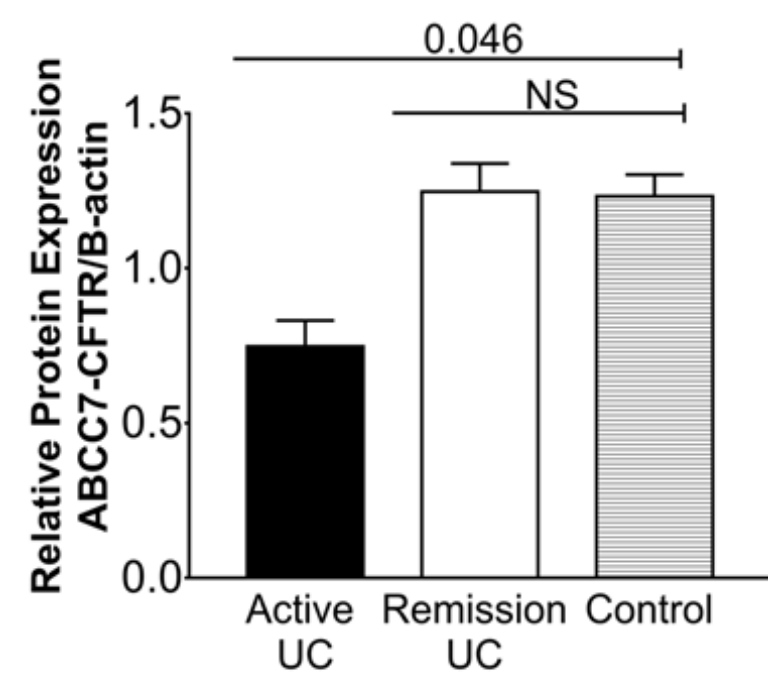

B

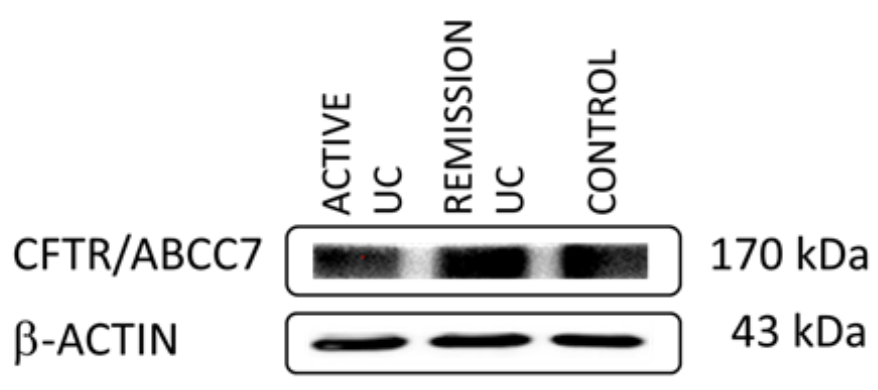

\section{Figure 2}

Relative gene protein expression of $A B C C 7 / C F T R$ in biopsies of UC patients. The relative protein expressions of $A B C 7 / C F T R$ were compared in biopsies of patients with active, remission UC and control group (Figure 2A). The qualitative protein expression is showed in figure $2 \mathrm{~B}$ and was performed by Western blot analysis. The medians of relative expression in the tree groups were compared with by Dunn's method for all pairwise multiple comparison procedure. 


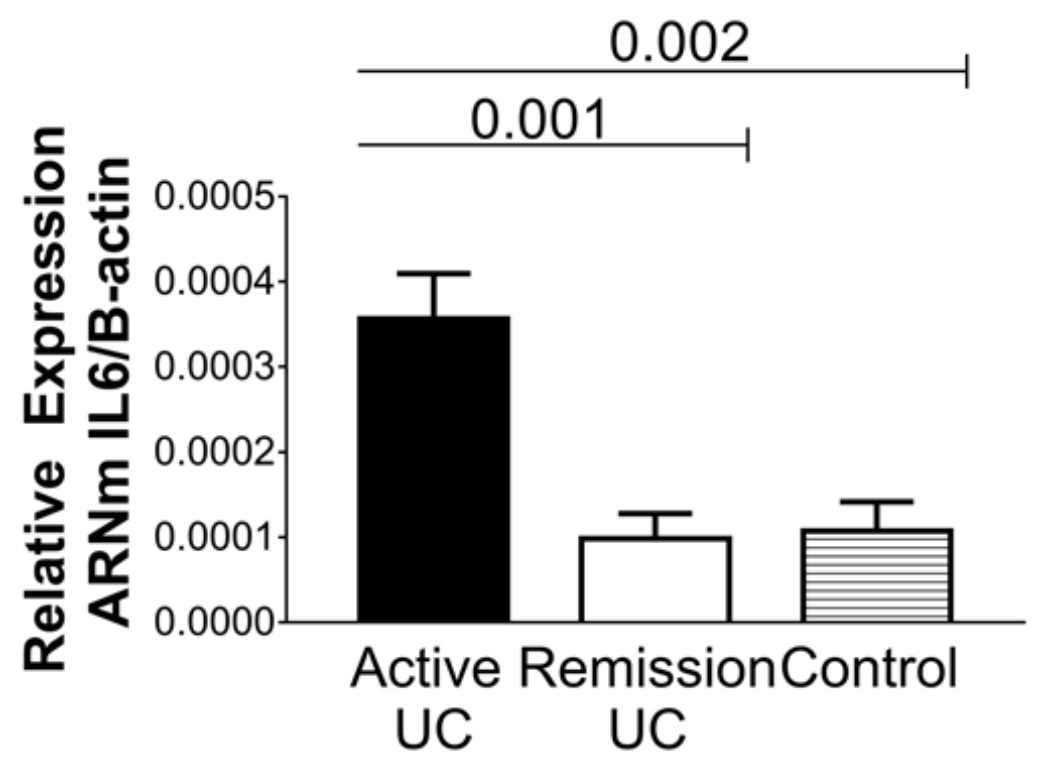

Figure 3

Relative gene expression of IL6 in colonic biopsies of UC patients. The relative gene expression of IL6 was employed as a inflammation marker and also was compared in patients with active, remission UC and control group for confirmed the histological diagnosis. The medians of relative expression in the tree groups were compared with $\mathrm{H}$-Kruskall Wallis and individual groups were analyzed by U-Mann-Withney test. 